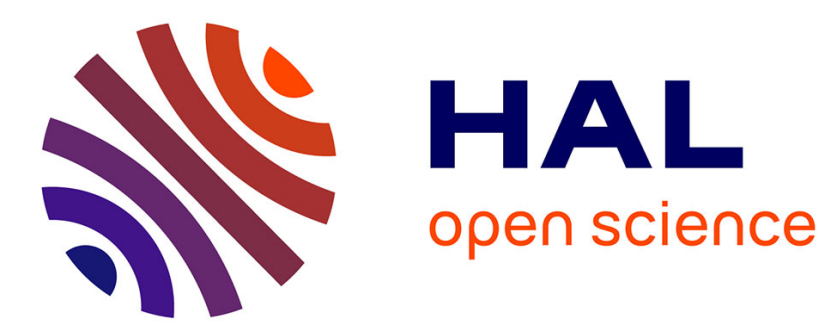

\title{
CHARACTERIZATION AND OPTIMIZATION OF THE LPCVD SILICON OXYNITRIDE PROCESS, USING THE DESIGN OF EXPERIMENTS METHOD
}

L. de Legé, M. Hendriks

\section{- To cite this version:}

L. de Legé, M. Hendriks. CHARACTERIZATION AND OPTIMIZATION OF THE LPCVD SILICON OXYNITRIDE PROCESS, USING THE DESIGN OF EXPERIMENTS METHOD. Journal de Physique IV Proceedings, 1991, 02 (C2), pp.C2-47-C2-54. 10.1051/jp4:1991205 • jpa-00249772

HAL Id: jpa-00249772

https://hal.science/jpa-00249772

Submitted on 1 Jan 1991

HAL is a multi-disciplinary open access archive for the deposit and dissemination of scientific research documents, whether they are published or not. The documents may come from teaching and research institutions in France or abroad, or from public or private research centers.
L'archive ouverte pluridisciplinaire HAL, est destinée au dépôt et à la diffusion de documents scientifiques de niveau recherche, publiés ou non, émanant des établissements d'enseignement et de recherche français ou étrangers, des laboratoires publics ou privés. 


\title{
CHARACTERIZATION AND OPTIMIZATION OF THE LPCVD SILICON OXYNITRIDE PROCESS, USING THE DESIGN OF EXPERIMENTS METHOD
}

\author{
L.J. de LEGÉ and M. HENDRIKS \\ ASM Micro Electronics Technology Centre, P.O. BOX 100, 3720 AC \\ Bilthoven, The Netherlands
}

\begin{abstract}
The LPCVD of silicon oxynitride has been characterized and optimized using the Design of Experiments method. The data of a half factorial matrix were converted with multiple linear regression analysis into an adequate empirical model: it appeared to be possible to predict the process output parameters (e.g. deposition rate), when applying more or less random input parameters (e.g. process pressure). The method supplies a tool to optimize a process in an efficient way: the optimum settings, found for the silicon oxynitride process are: temperature $800^{\circ} \mathrm{C}$, ramp $\pm 8^{\circ} \mathrm{C}$, pressure $400 \mathrm{mTorr}$, DCS flow $70 \mathrm{sccm},\left(\mathrm{N}_{2} \mathrm{O}+\mathrm{NH}_{3}\right) / \mathrm{DCS}=3$, $\mathrm{NH}_{3} / \mathrm{N}_{2} \mathrm{O}=0.18$. Corresponding predicted output parameters are: deposition rate $14.2 \AA / m i n .$, uniformity over the wafer $\pm 2 \%$ and the uniformity over the boat $0 \%$. The refractive index becomes $1.70 \pm 0.01$.
\end{abstract}

\section{Introduction.}

In an Integrated Circuit production process, oxidation masks are required. For this purpose, LPCVD silicon nitride is standard used. However, this film is afflicted with a very high mechanical stress. Therefore, it is necessary to grow a thin thermal stress relief oxide between the silicon substrate and the nitride film. This stress relief oxide results in the formation of the birds beak in LOCOS structures. The LPCVD silicon oxynitride film has a reduced stress and can be deposited directly on the silicon substrate [1-4]. In the oxynitride process, $\mathrm{N}_{2} \mathrm{O}$ is used as a process gas in addition to $\mathrm{SiH}_{2} \mathrm{Cl}_{2}(\mathrm{DCS})$ and $\mathrm{NH}_{3}$. Consequently, both at the input side (extra gas applied) and at the output side (change in film composition) we have extra degrees of freedom and the oxynitride process becomes substantially more complex than the silicon nitride process. Therefore, the Design of Experiments method is applied to establish the relation between process input and output parameters in a systematic way. 


\section{Experimental.}

\subsection{Equipment and measurement procedures}

The oxynitride process was evaluated in a ASM LPCVD hot wall reactor with a $200 \mathrm{~mm} \mathrm{ID}$ process tube and a load of 150 wafers (diameter $125 \mathrm{~mm}$ ), placed at a spacing of $4.76 \mathrm{~mm}$. As process gases, $\mathrm{SiH}_{2} \mathrm{Cl}_{2}, \mathrm{NH}_{3}$ and $\mathrm{N}_{2} \mathrm{O}$ were used. The process pressure was measured by a non-heated MKS baratron, type $122 \mathrm{~B}$, and pressure regulation was realized by means of a butterfly valve. A deposition time of $60 \mathrm{~min}$ was used for all runs. Film thickness and refractive index were measured with a Tylan Tyger multiple angle reflectometer.

\subsection{Design of Experiment.}

The selection of relevant process parameters and the range over which they have been varied is shown in table I. As basic design, a half factorial scheme, with the process input parameters at two levels was chosen. This allows full characterization of the main and the interaction effects on the process. All data obtained were processed using Systat, a statistic program for the Macintosh personal computer. Systat applies multiple linear regression analysis.

Table I: $\quad$ Range over which parameters were varied in the 210 furnace.

\begin{tabular}{|l|c|c|c|c|}
\hline variable & $\begin{array}{c}\text { symbol used } \\
\text { in text }\end{array}$ & \multicolumn{3}{|c|}{ oxynitride 210 process } \\
\hline & & low & centre & high \\
\cline { 2 - 5 } Temperature $\left({ }^{\circ} \mathrm{C}\right)$ & $\mathrm{T}$ & 800 & 820 & 840 \\
Temp. ramp $\left({ }^{\circ} \mathrm{C}\right)$ & $\mathrm{DT}$ & \pm 0 & \pm 20 & \pm 40 \\
Pressure $(\mathrm{mT} T \mathrm{rr})$ & $\mathrm{P}$ & 300 & 350 & 400 \\
DCS $(\mathrm{sccm})$ & $\mathrm{DCS}$ & 50 & 70 & 90 \\
$(\mathrm{~N} 2 \mathrm{O}+\mathrm{NH} 3 / \mathrm{DCS}(-)$ & $\mathrm{RDCS}$ & 2 & 3 & 4 \\
$\mathrm{NH} 3 / \mathrm{N} 2 \mathrm{O}(-)$ & $\mathrm{RNH3}$ & $2 / 12$ & $3 / 12$ & $4 / 12$ \\
\hline
\end{tabular}

Unfortunately, the relatively large number of process parameters (six) will result in a rather extensive number of experiments $\left(2^{6-1}=2^{5}=32\right)$. However, the temperature ramp is expected to influence only the down boat uniformity. For practical reasons, it is obviously important to know the sensitivity of this effect, but incorporating the temperature ramp in the experimental matrix is a rather cumbersome manner to achieve this. As an alternative approach, it is decided to leave the temperature ramp out of the matrix and determine the effect of temperature ramp separately, keeping the level of the other parameters constant and varying the temperature ramp only.

The complete matrix of experiments is given in table II. It comprises a half factorial matrix for five parameters at two levels $\left(2^{5-1}=2^{4}=16\right.$ experiments) in randomized order, five added centre points (run 1, 9, 10,20 and 21) to evaluate the reproducibility and three runs to determine the effect of temperature ramp ( run 22, 23 and 24). 
Table II: Complete matrix of experiments to describe the silicon oxynitride process. Settings are normalized: -, 0, + respectively stand for low, centre and high level of the input parameter.

\begin{tabular}{|c|c|c|c|c|c|c|}
\hline Run & $T$ & DT & $P$ & DCS & RDCS & RNH3 \\
\hline 1 & 0 & 0 & 0 & 0 & 0 & 0 \\
2 & + & 0 & - & + & + & - \\
3 & - & 0 & - & - & + & - \\
4 & + & 0 & + & + & - & - \\
5 & + & 0 & + & - & + & - \\
6 & + & 0 & - & - & + & + \\
7 & - & 0 & + & + & - & + \\
8 & - & 0 & - & + & - & - \\
9 & 0 & 0 & 0 & 0 & 0 & 0 \\
10 & 0 & 0 & 0 & 0 & 0 & 0 \\
11 & - & 0 & - & + & + & + \\
12 & + & 0 & - & + & - & + \\
13 & - & 0 & + & - & - & - \\
14 & + & 0 & - & - & - & - \\
15 & + & 0 & + & + & + & + \\
16 & + & 0 & + & - & - & + \\
17 & - & 0 & + & - & + & + \\
18 & - & 0 & - & - & - & + \\
19 & - & 0 & + & + & + & - \\
20 & 0 & 0 & 0 & 0 & 0 & 0 \\
21 & 0 & 0 & 0 & 0 & 0 & 0 \\
22 & 0 & 0 & 0 & 0 & 0 & 0 \\
23 & 0 & - & 0 & 0 & 0 & 0 \\
24 & 0 & + & 0 & 0 & 0 & 0 \\
\hline
\end{tabular}

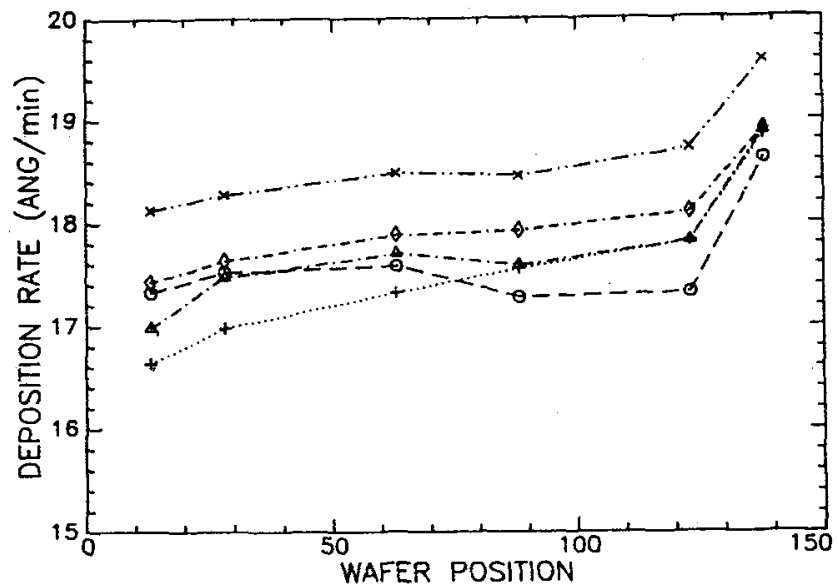

Figure 1 The deposition rate versus the wafer position : down boat uniformity. The wafers are numbered 1 to 150 from door to pump side. The symbols stand for: 0- run 1, $\Delta$-run 9,+-run 10, $\mathrm{x}$ - run 20 and $\checkmark$ - run 21 (see table II). 


\section{Results and discussion.}

The down boat profile in deposition rate for the five centre runs is presented in figure 1. It can be observed that the depletion is overcompensated by the $\pm 20^{\circ} \mathrm{C}$ temperature ramp. The reproducibility of the process is reasonable. It should be noted that the experiments were carried out over a three weeks time period.

A first indication of the sensitivity of the results for certain process parameters is obtained by the Pearson correlation matrix, see table III. In this table the abbreviation dep.rate stands for the deposition rate in $\AA / \mathrm{min}$. The p/p stands for the thickness uniformity over the wafer and $w / w$ stands for the thickness uniformity over the length of the boat. The first uniformity is defined as ( $\max -\min ) /(2 \mathrm{xavg})$ in $\%$ and the latter is defined as (centre first wafer - centre last wafer) / ( $2 \times$ avg), also in \%. The first wafer is placed near the gas inlet side and the last wafer at the pump side.As a consequence, a negative $\mathrm{w} / \mathrm{w}$ means an increasing film thickness towards the pump side. RI stands for the refractive index of the film and DRI is the variation of this RI over the boat. In this matrix, $\cdot a$ high and positive number means a strong correlation between input and output parameter. At a negative sign, the parameters show a negative correlation. The Pearson matrix reveals that the refractive index is primarily determined by $\mathrm{RNH}_{3}\left(=\mathrm{NH}_{3} / \mathrm{N}_{2} \mathrm{O}\right.$ ratio). A lower ratio results in a lower refractive index, because of the positive correlation coefficient. This can be expected: a lower $\mathrm{NH}_{3} / \mathrm{N}_{2} \mathrm{O}$ ratio gives a film which is more similar to silicon oxide (RI of silicon oxide $=1.46$, RI of silicon nitride $=1.99$ ).

Table III: Pearson correlation matrix, calculated for the silicon oxynitride process.

\begin{tabular}{|c|c|c|c|c|c|c|c|c|c|}
\hline & $\mathbf{T}$ & DT & $\mathbf{P}$ & DCS & RDCS & RNH3 & $\mathrm{N} 2 \mathrm{O}$ & NH3 & TFLOW \\
\hline ep.rate & 0.62 & -0.01 & 0.49 & 0.22 & -0.14 & 0.49 & -0.06 & 0.28 & 0.06 \\
\hline$p / p$ & 0.58 & -0.09 & 0.47 & -0.18 & -0.35 & -0.16 & -0.35 & -0.43 & -0.37 \\
\hline$w / w$ & 0.43 & -0.43 & 0.35 & -0.46 & -0.31 & 0.39 & -0.57 & -0.26 & -0.54 \\
\hline$R I$ & -0.37 & 0.02 & -0.05 & 0.24 & 0.29 & 0.81 & 0.23 & 0.72 & 0.35 \\
\hline$D R I$ & 0.39 & 0.24 & 0.38 & -0.35 & -0.54 & 0.19 & -0.64 & -0.46 & -0.61 \\
\hline
\end{tabular}

Furthermore the temperature also has a substantial influence on the refractive index. In all cases the refractive index showed lower values at the end of the boat. This effect is more pronounced at a higher temperature ramp. This is consistent with the temperature dependence of the refractive index. A higher temperature at the pump side results in a stronger decrease in refractive index there. This puts restrictions on the maximum temperature ramp that can be applied for optimizing the down boat profile in deposition rate. The point to point uniformity degrades at higher temperature and pressure. On the other hand larger RDCS $\left(=\left(\mathrm{N}_{2} \mathrm{O}+\mathrm{NH}_{3}\right) / \mathrm{DCS}\right.$ ratio) and larger DCS flow give a better uniformity over the wafer. The wafer to wafer uniformity is influenced by all process parameters to about the same extent in a sense as can be expected. Depletion is stronger for higher temperatures and pressures. This depletion is compensated by a higher value of the 
temperature ramp, the DCS flow, the RDCS and the $\mathrm{RNH}_{3}$. Finally, the deposition rate increases with temperature and pressure whereas a higher $\mathrm{RNH}_{3}$ decreases the deposition rate, due to dilution.

The silicon oxynitride process comprises 3 different gases. However, the $\mathrm{N}_{2} \mathrm{O}$ and $\mathrm{NH}_{3}$ flow were not used as direct process parameters. Instead, the DCS flow, $\left(\mathrm{N}_{2} \mathrm{O}+\right.$ $\mathrm{NH}_{3}$ ) / DCS ratio and $\mathrm{NH}_{3} / \mathrm{N}_{2} \mathrm{O}$ ratio were used as parameters. This choice is rather arbitrary and is based on literature data and experience. The use of $\mathrm{N}_{2} \mathrm{O}, \mathrm{NH}_{3}$ and total flow (TFLOW) is evaluated in the Pearson matrix of table III. It can be seen that $\mathrm{RNH}_{3}$ was the best choice with the highest correlation coefficients. For RDCS, however, $\mathrm{N}_{2} \mathrm{O}$ or TFLOW might be an adequate alternative. Looking in retrospect, the selection of the flows themselves, i.e. DCS, $\mathrm{N}_{2} \mathrm{O}$ and $\mathrm{NH}_{3}$ would not have been a bad choice at all, although the choice that was made for this study is probably the most optimum.

A more quantitative evaluation of the sensitivity of process parameters is achieved by determining linear empirical models, with the use of multiple regression. Only main effects appeared to be significant. Interaction effects (represented by the product of process input parameters) were not significant If we use normalized process parameters (values in terms of $-1,0,+1$ ) the results can be given in the form of the following equations:

$$
\begin{aligned}
& \text { dep rate }=17.6+3.8 \cdot T+2.9 \cdot P+1.3 \cdot D C S-0.9 \cdot R D C S+2.9 \cdot R^{2} H_{3}(1) \\
& \mathrm{p}-\mathrm{p} \quad=\quad 2.2+0.9 \cdot T+0.7 \cdot P \quad-0.5 \cdot R D C S \\
& \mathrm{w}-\mathrm{w}=-4.1+6.4 \cdot T-17.9 \cdot D T+5.1 \cdot P-6.8 \cdot D C S-4.6 \cdot R D C S+5.7 \cdot R^{-}=H_{3}(3) \\
& \mathrm{RI} \times 10^{2}=171.6-1.8 \cdot \mathrm{T}+1.2 \cdot \mathrm{DCS}+1.4 \cdot \mathrm{RDCS}+4.0 \cdot \mathrm{RNH}_{3}(4) \\
& \text { DRI } \times 10^{3}=16.2+4.3 \cdot T+7.5 \cdot D T+4.2 \cdot P-3.8 \cdot D C S-5.9 \cdot R D C S
\end{aligned}
$$

It should be noted that the constant is the average result (e.g. the RI) of all runs together. The relation between normalized (in italics) and absolute process parameter values is as follows:

$$
X_{\text {norm }}=\frac{X-X_{\text {centre }}}{X_{\text {high }}-X_{\text {centre }}}
$$

This works out in the following way:

$\begin{array}{llc}T_{\text {norm }} & = & (\mathrm{T}-820) / 20 \\ D T_{\text {norm }} & = & (\mathrm{DT}-20) / 20 \\ P_{\text {norm }} & = & (\mathrm{P}-350) / 50 \\ D C S_{\text {norm }} & = & (\mathrm{DCS}-70) / 20 \\ \text { RDCS }_{\text {norm }} & = & (\mathrm{RDCS}-3) / 1 \\ R N H_{3_{\text {norm }}}= & \left(\mathrm{RNH}_{3}-3 / 12\right) /(1 / 12)\end{array}$

Equations 1 to 5 can be visualized by means of contour plots. The most relevant contour plots are shown in figures 2 to 6 as an illustration of the results obtained. 


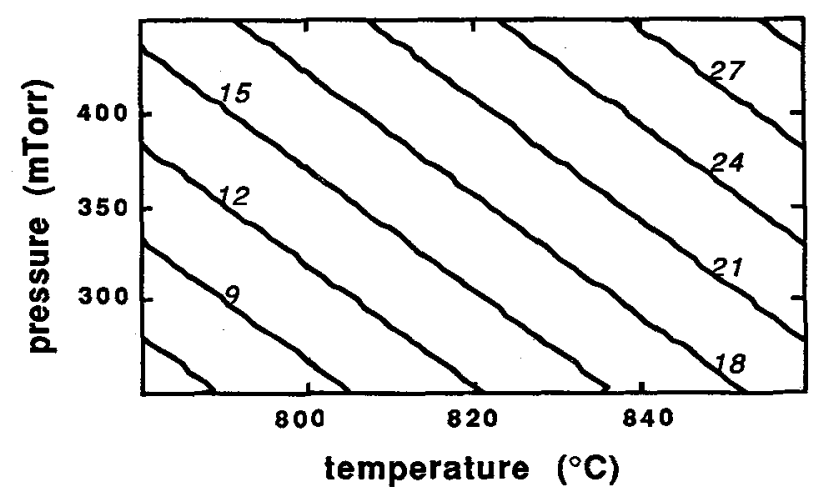

Figure 2 Contour plot of the deposition rate (A/min) versus the pressure and the temperature.

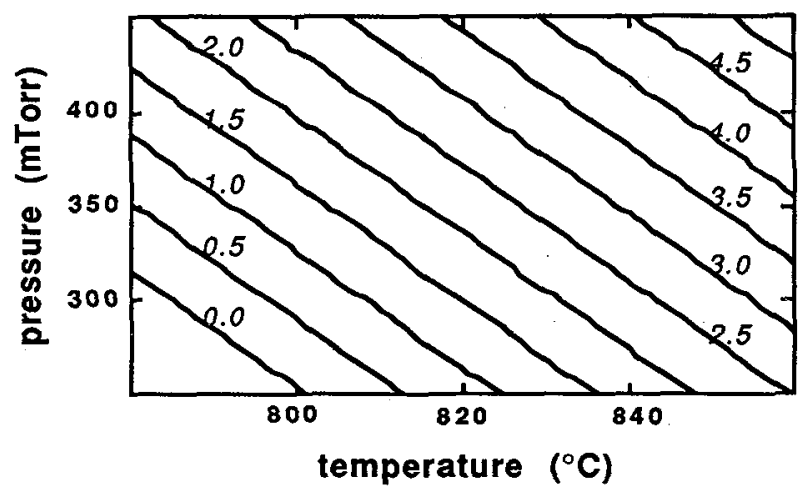

Figure 3 Contour plot of the point to point uniformity (absolute range, $\pm \%$ ) versus pressure and temperature.

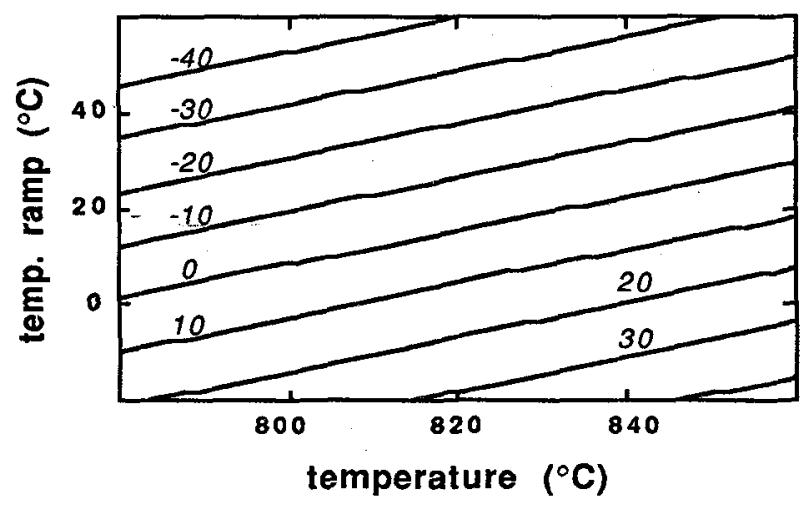

Figure 4 Contour plot of the wafer to wafer uniformity (absolute range, $\pm \%$ ) versus the temperature and the temperature ramp. 


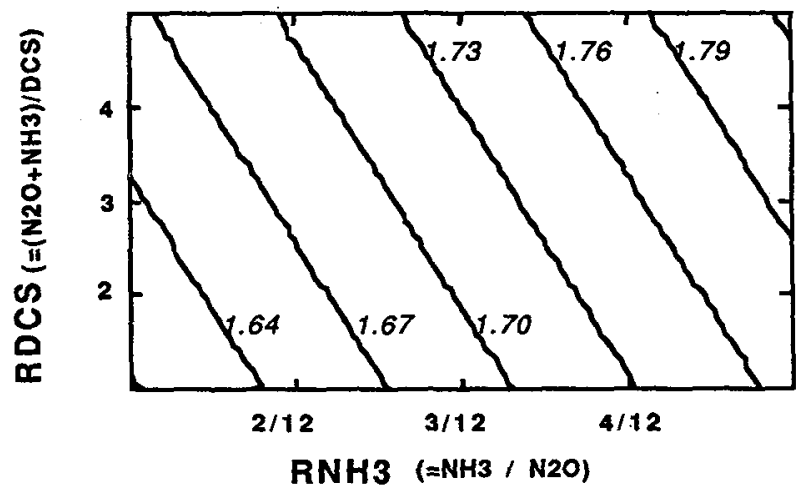

Figure 5 Contour plot of refractive index versus the RDCS and the $\mathrm{RNH}_{3}$.

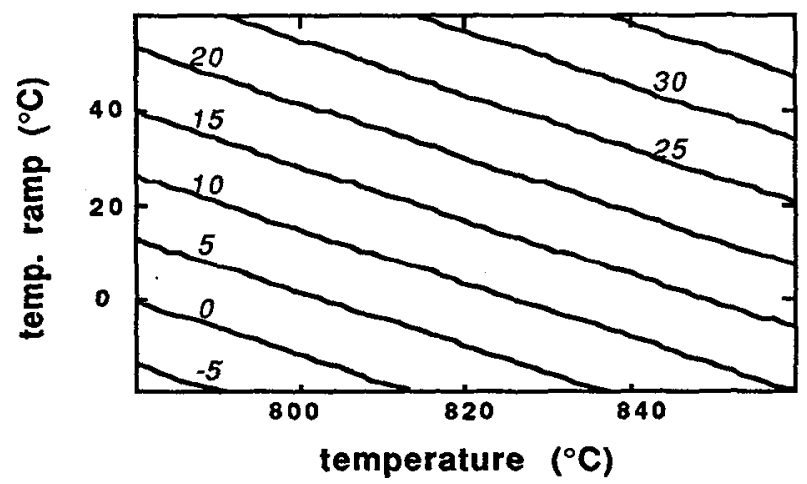

Figure 6 Contour plot for down boat variation of the refractive index $\left(x 10^{3}\right)$ versus temperature and temperature ramp.

The consistency of the model was checked experimentally. Two runs were carried out at a combination of settings that was not used in the matrix. The predicted results and real results are compared in table IV.For reference, the standard error of estimate is given. A quite good agreement was achieved, in particular for the deposition rate, the $p / p$ uniformity and the refractive index in Run 1. It should be noted, however, that the parameters for Run 2 have a value that lies beyond the range investigated. Consequently, the empirical model, described by equations 1 to 5 allows to predict optimized process parameters. Settings that yield a " $0 \%$ " $w / w$ uniformity or a refractive index.of 1.70 , derived from the model are: temperature $800^{\circ} \mathrm{C}$, temperature ramp $\pm 8^{\circ} \mathrm{C}$, pressure 400 mTorr, DCS flow $70 \mathrm{sccm}$, $\left(\mathrm{N}_{2} \mathrm{O}+\mathrm{NH}_{3}\right) / \mathrm{DCS}$ ratio 3 and $\mathrm{NH}_{3} / \mathrm{N}_{2} \mathrm{O}$ ratio 0.18 . The other output parameters then become: deposition rate $14.2 \AA / \mathrm{min}$ and uniformity over the wafer $\pm 2 \%$. 
Table IV: Normalized settings for two test runs and a comparison between predicted and real experimental results.

\begin{tabular}{|c|c|c|c|c|c|c|c|}
\hline & \multicolumn{6}{|c|}{ Normalized settings: } \\
\hline & & $T$ & DT & $p$ & DCS & RDCS & $\mathrm{RNH}_{3}$ \\
\hline & & $\begin{array}{r}-0.5 \\
+1.5\end{array}$ & $\begin{array}{r}0 \\
+0.5\end{array}$ & $\begin{array}{l}+0.8 \\
-0.8\end{array}$ & $\begin{array}{l}+0.5 \\
+1.5\end{array}$ & $\begin{array}{r}-0.5 \\
+1.5\end{array}$ & $\begin{array}{l}+0.5 \\
-1.3\end{array}$ \\
\hline & & \multicolumn{6}{|l|}{ Results: } \\
\hline \multirow[b]{2}{*}{ run 1} & \multirow[b]{2}{*}{$\begin{array}{l}\text { predicted } \\
\text { experiment }\end{array}$} & $\begin{array}{l}\text { RI } \\
(-)\end{array}$ & $\begin{array}{l}\text { DRI } \\
.10^{3}\end{array}$ & $\begin{array}{c}\text { Dep. rate } \\
\text { (A/min) }\end{array}$ & $\begin{array}{l}p / p \\
(\%)\end{array}$ & $\begin{array}{l}\text { w/w } \\
(\%)\end{array}$ & \\
\hline & & $\begin{array}{l}1.743 \\
1.747\end{array}$ & $\begin{array}{l}18 \\
28\end{array}$ & $\begin{array}{l}20.5 \\
20.3\end{array}$ & $\begin{array}{l}2.6 \\
1.7\end{array}$ & $\begin{array}{r}1.6 \\
-3.1\end{array}$ & \\
\hline run 2 & $\begin{array}{l}\text { predicted } \\
\text { experiment }\end{array}$ & $\begin{array}{l}1.676 \\
1.651\end{array}$ & $\begin{array}{r}8 \\
13\end{array}$ & $\begin{array}{l}17.8 \\
14.5\end{array}$ & $\begin{array}{l}2.2 \\
2.0\end{array}$ & $\begin{array}{l}-32.0 \\
-26.8\end{array}$ & \\
\hline $\begin{array}{l}s t a r \\
\text { of } p\end{array}$ & $\begin{array}{l}\text { idard error } \\
\text { rediction }( \pm)\end{array}$ & 0.011 & 5.0 & 1.5 & 0.7 & 3.2 & \\
\hline
\end{tabular}

\section{Conclusions}

The silicon oxynitride process characterization very well illustrates the potentialities of the Design of Experiments method. Based on empirically determined models, optimum process settings can be determined in a systematic way. The refractive index of the oxynitride film is predominantly determined by the $\mathrm{NH}_{3} / \mathrm{N}_{2} \mathrm{O}$ ratio. The temperature ramp along the length of the boat should be kept limited to achieve a good uniformity in film thickness and refractive index simultaneously.

\section{References.}

1/ KUIPER A.E.T., KOO S.W., HABRAKEN F.H.P.M. and TAMMINGA Y., J. Vac. Sci. Technol. B1, 1 (1983) 621.1

12/ HABRAKEN F.H.P.M., TIJHAAR R.H.G., VAN DER WEG W.F., KUIPER A.E.T. and . WILLEMSEN M.F.C, J. Appl. Phys., 59 (1986) 447.

3/ OUDE ELFERINK J.B., HABRAKEN F.H.P.M., VAN DER WEG W.F. and KUIPER A.E.T., Applied Surface science, 33/34 (1988) 765.

14/ KUIPER A.E.T., WILLEMSEN M.F.C., MULDER J.M.L., OUDE ELFERINK J.B., HABRAKEN F.H.P.M. and VAN DER WEG W.F., J. Vac. Sci. Technol. B7, 3 (1989) 455. 